\title{
Aerodynamic Analysis of Flapping Wing over Fixed Wing
}

\author{
Md Jalal Uddin Rumi, Nc Chattopadhyay, and Md Abdus Salam
}

\begin{abstract}
The need for the study of an ornithopter is based on the argument that flapping wing flight, at small scale, is more efficient than traditional fixed wing and rotary flight. Flapping wing flight more closely mimics natural flight and has potential for being lower in weight and having greater endurance. Recent approaches involve analyzing bird, bat and insect flight which enabled understanding of the mechanisms that biological 'machines' that use flapping to provide lift and thrust. It is known that the flexible nature of membrane type wings can increase aerodynamic stability by damping unsteady forces/moments and storing elastic energy. The objective of this study is to analyze relative merits of a flapping wing over a fixed wing. This paper primarily focuses on the role of wing flexibility in flapping wing flight. The study of two wings, various flapping frequencies and air flows will help future researchers in perhaps eventually building a flapping wing UAV with flexible membrane wings.
\end{abstract}

Index Terms-Endurance, flapping, ornithopter and stability.

\section{INTRODUCTION}

Over the past twenty-five years, interest in smallunmanned aerial vehicles (UAVs) has greatly increased. Most of the UAVs in production and use today are fixed wing airplanes, which mean that these aero planes employ traditional methods of lift and thrust: a propeller for thrust and rigidly attached wings relying heavily on the free stream velocity for lift. Tasks of these vehicles include surveillance, communication relay links, decoys, and detection of biological, chemical and radiological materials. However, there is another realm of UAVs that is just beginning to be explored, those which utilize flapping wings. These types of vehicles are also known as ornithopters.

\section{DEVELOPMENT OF ORNITHOPTER}

Need for the development of an ornithopter is based on the argument that flapping wing flight, at small scale, is more efficient than traditional fixed wing and rotary flight. Flapping wing flight more closely mimics natural flight and has potential for being lower in weight and having greater

Manuscript received April 10, 2013; revised July 16, 2013.

Md Jalal Uddin Rumi is with Department of Aeronautical Engineering, Military Institute of Science and Technology, Dhaka-1216, Bangladesh (email: jalal.uddin_rumi@yahoo.com).

Nc Chattopadhyay is from Indian Air force, now is with Aeronautical Engineering Dept. of Military Institute of Science and Technology, Dhaka1216, Bangladesh (e-mail: ncchatto@rediffmail.com).

Md Abdus Salam is with Engineering Dept. of Military Institute of Science and Technology, Dhaka 1216, Bangladesh (e-mail: timamtaranni@yahoo.com). endurance [1]. In addition, strategic and stealth applications for flapping wing vehicles are evident as well, as they mimic natural flyers and could steal their presence. Thus, flapping wing air vehicles may provide a significant advantage over their fixed-wing counterparts [1] especially in tactical military applications.

\section{RECENT ANALYSIS OF VARIOUS MECHANISMS}

In analyzing natural flyers, the issue of wing flexibility has emerged, since many insect and bird wings have complex elastic structures. The flexible nature of membrane type wings can actually increase aerodynamic stability by damping unsteady forces/moments and storing elastic energy [2]. While some vehicles and mechanisms that utilize flapping wing flight have been demonstrated [3], few have been successful.

\section{OBJECTIVE OF THE STUDY}

The objective of this paper is to highlight salient aspects of flapping wing and analyze different advantages of this over fixed wing mechanism.

\section{LifT GENERATION IN FLAPPING WING FLIGHT}

For a comprehensive understanding of flapping wing flight, it is necessary to observe when and how lift is generated during a flapping cycle. A typical cycle in the flight of a flapping wing vehicle consists of a down stroke and an upstroke (Fig. 1). Lift generation on the various strokes of a flat rigid plate have been studied by Hong et al. [4].Assuming the wing starts from a maximum height position

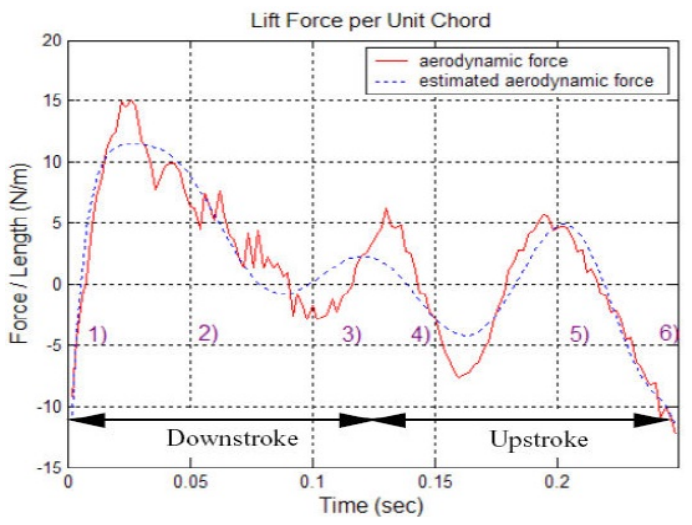

Fig. 1. Unit force vs. time for up and down strokes [4].

1) Start of the Down Stroke: The lift starts to increase due 
to vertical air reaction.

2) Actual down Stroke: The aerodynamic force peaks.

3) End of the Down Stroke: The lift force starts to decrease.

4) Actual Upstroke: Aerodynamic forces create negative lift as the wing travels upwards.

\section{Thrust GENERATION IN FLAPPING Wing Flight}

In natural flyers, it has been shown that insects take advantage of unsteady aerodynamic phenomena to generate thrusts. The generation of thrust can be broken into 4 parts [4]:

1) Start of down stroke: The wing translates with a fixed collective pitch angle.

2) End of the down Stroke: The wing turns so that the blade angle of attack is positive on the upstroke.

3) Actual Upstroke: The angle of attack is still positive here.

4) End Of The Upstroke/Beginning Of The Down Stroke: The wing's angle of attack changes from positive to negative.

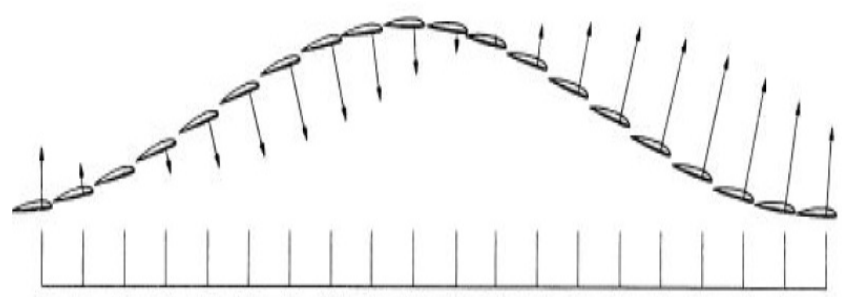

$\begin{array}{llllllllllllllllllll}18 & 36 & 54 & 72 & 90 & 108 & 126 & 144 & 162 & 180 & 198 & 216 & 234 & 252 & 270 & 288 & 306 & 324 & 342 & 360\end{array}$ Fig. 2. Lift and thrust generation vs. phase [5].

Fig. 2 shows the lift and thrust generation with respect to the phase of a flapping airfoil [4]. The wing starts at a point, labeled as $18^{\circ}$, and then proceeds to complete one full flap (traveling $360^{\circ}$ ) and returning to its starting position. The arrows point the direction of flapping force which on vector resolution split into lift and thrust force. In one cycle of $3 \mathrm{~Hz}$ frequency, the net lift gain is seen zero so the height of flight is fixed with the net forward thrust.

\section{POWER TO FLY}

The power necessary to achieve flapping flight can be calculated by using formulas derived by Azuma2, 1992[6] and the equations are plotted in the graphs shown below. This power is mainly a function of the following variables: vehicle mass, flapping frequency, forward speed, wing chord, wing span, and wing beat amplitude. Example calculations for a vehicle weighing $50 \mathrm{~g}$ and having an ideal $100 \%$ efficient Reciprocating Chemical Muscle (RCM) is given.

Based on this analysis, approximately one watt of power would be necessary to propel an ornithopter of $50 \mathrm{gm}$ at 5 $\mathrm{m} / \mathrm{sec}$. For comparison, several plots of the necessary power versus forward velocity and mass are provided in Fig. 3.Doubling the mass of the ornithopter results in almost eight times the required power.

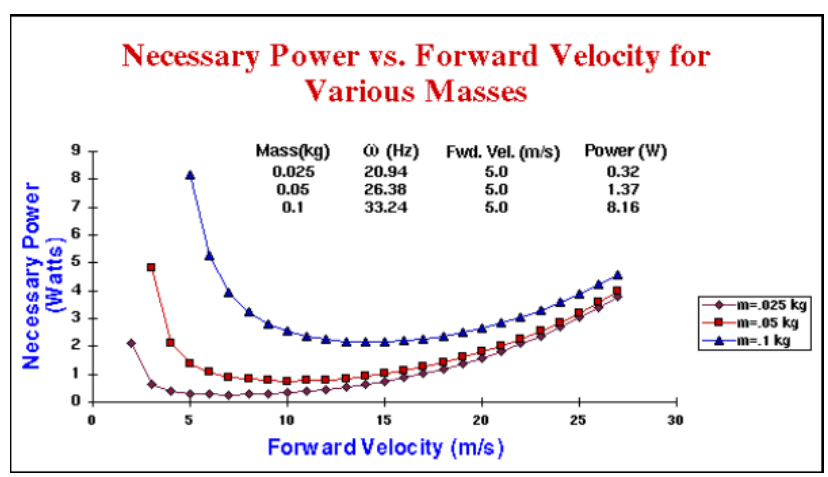

Fig. 3. Graph of necessary power vs. Forward velocity for various masses [7].

\section{FLEXIBLE WINGS VERSUS RIGID WINGS}

It has been shown that flapping wing based UAVs have certain advantages compared to their fixed wing counterparts:

1) Ability to hover reacts more efficiently to gusts, have lower weight, and generate lift without excessive size and weight [8].

2) Flexible wings have also been shown to be more advantageous than rigid wings, with having higher stall angles by performing adaptive washout, and providing smoother flight.

3) The main advantage of flexible wings is that they facilitate shape adaptation, essentially adapting to the airflow to provide a smoother flight. A wing changes shape as a function of angle of attack and wind speed [8]. This adaptive washout is produced through extension of the membrane and twisting of the structural members, resulting in angle of attack changes along the span of the wing in response to the oncoming flow [9].

4) With a decrease in relative airspeed, the angle of attack of the wing increases, and the wing becomes more efficient, resulting in near constant lift. This enables a UAV with flexible wings to fly with exceptional smoothness, even in gusty conditions.

\section{RECOMMENDATION FOR FUTURE STUDIES}

Due to the aerodynamic advantages of flapping wing over fixed wing, more studies should continue across the globe for further reveal its more advantages and aspects. It is just a starting approach. Due to the limitation of lab facilities and financial problem further studies could not be continued. But regarding the huge prospect of this topic, we are looking forward to do further aerodynamic analysis of flapping wing and its approach to practical aviation world.

\section{CONCLUSION}

Lift and thrust generation of a conventional flight is well established in classical aerodynamics. The flapping wing is a specialized breed of flying machines that mimics the natural flyers. As such, these special flights need a focused approach to analyze aerodynamic aspects of natural flight. Various researches and studies in this field highlighted that 
a flexible wing of an ornithopter is highly adaptive and elastically resilient while adding thrust in flapping motion, which reduces the power consumption and indicative of high propulsive efficiency. However, the mechanical linkage and complex mechanisms for flapping system poses limitation in extensive use of ornithopters in general aviation use. With the advent of advanced technologies, easier and simple systems may evolve with light weight flexible wings that can become a conventional flying machine of the future with additive stealth dimension.

\section{REFERENCES}

[1] C. P. Ellington, "The novel aerodynamics of insect flight: Application to micro air-vehicles," Journal of Experimental Biology, vol. 202, no. 23, pp. 3439-3448, Dec. 1999.

[2] Ellington and P. Charles, "Insects versus birds: The great divide," 44th AIAA Aerpspace Sciences Meeting and Exhibit, Reno, Nevada, Jan. 2006.

[3] Mueller, J. Thomas, DeLaurier, and D. James, "Aerodynamics of small vehicles," Аnnu. Rev. Fluid Mech, vol. 35, pp. 89-111, 2003.

[4] Y. S. Hong and A. Altman, "An experimental study on lift force generation resulting from span wise flow in flapping wings," 44th AIAA Aerospace Sciences Meeting and Exhibit, Reno, Nevada. Sept. 2006.

[5] DeLaurier and D. James, "The development of a full scale ornithopter wing" The Aeronautical Journal of the Royal Aeronautical Society, May 1993.

[6] Dragos viieru, Flapping and Fixed Wing Aerodynamics of Low Reynolds Number Flight Vehicles, University of Florida, 2006.

[7] R. C. Michelson, "Update on flapping wing Micro Air Vehicle research ongoing work to develop a flapping wing," in Proc. 13th Bristol International RP V Conference.

[8] P. G. Ifju, A. D. Jenkins, S. Ettingers, Y. Lian, and W. Shyy, "Flexible-wing- based micro air vehicles," 40th AIAA Aerospace Sciences Meeting and Exhibit, Reno, Nevada. Jan. 14-17, 2002.

[9] P. G. Ifju, G. Peter, B. Stanford, and M. Sytsma, "Analysis of a flexible wing micro air vehicle," in Proc. 25th AIAA Aerodynamic Measurement Technology and Ground Testing Conference, San Francisco, California, June 5-8, 2006.

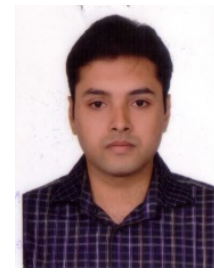

Md Jalal Uddin Rumi is completing his Bachelor of Science in Aeronautical Engineering from Military Institute of Science and Technology, Mirpur Cantonment, Dhaka, Bangladesh with a current CGPA 3.67. His birth date is $11^{\text {th }}$ may 1991 .

$\mathrm{He}$ is a student member of American Society of Mechanical Engineers (ASME), Royal Aeronautical Society and Associate of NDT division at Atomic Energy Commission, Bangladesh. He has attended several national and international conferences and seminars. He has several publications in different conference proceedings and journals which are nationally and internationally reputed.

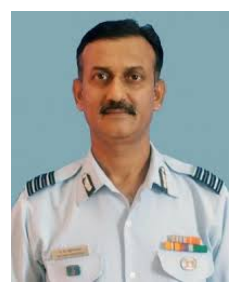

Nc Chattopadhyay is a senior instructor of the Department of Aeronautical Engineering (AE) in Military Institute of Science and Technology, Mirpur Cantonment, Dhaka, Bangladesh.

He has 27years of working experience as Group Captain in Bangladesh Air force. His teaching interests are Thermodynamics, Aeronautical Engineering, Production Process, and Applied Aerodynamics, Turbo Machinery, Propulsion.

Chattopadhyay has attended several national and international conferences and seminars. He has several publications in different conference proceedings and journals which are nationally and internationally reputed.

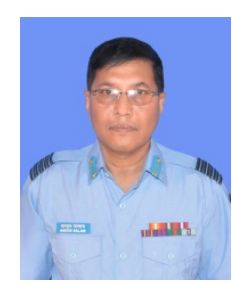

Md Abdus Salam is a senior instructor and head of the Department Department of Aeronautical Engineering (AE) in Military Institute of Science and Technology, Mirpur Cantonment, Dhaka, Bangladesh. His Masters of Science in Aeronautical Engineering is completed from University of Aeronautics and Astronautics, China. He has also done Masters of Defence from Studies Bangladesh National University (NU).

He has 24years of working experience as Group Captain in Bangladesh Air force. His teaching interests are Thermodynamics, Aeronautical Engineering, Production Process, and Applied Aerodynamics.

Salam has attended several national and international conferences and seminars. He has several publications in different conference proceedings and journals which are nationally and internationally reputed. 